\title{
Decoupling of Dissolved Stable Barium and Silicon Isotope Signatures in the Congo River Plume
}

\author{
ZHOULING ZHANG ${ }^{1}$, YANG YU ${ }^{1}$, ED HATHORNE ${ }^{1}$, \\ LUCIA HELENA VIEIRA ${ }^{2}$, PATRICIA GRASSE ${ }^{3}$ AND \\ MARTIN FRANK ${ }^{1}$ \\ ${ }^{1}$ GEOMAR Helmholtz Centre for Ocean Research Kiel \\ ${ }^{2}$ Alfred Wegener Institute, Helmholtz Centre for Polar and \\ Marine Research \\ ${ }^{3}$ German Centre for Integrative Biodiversity Research (iDiv) \\ Halle-Jena-Leipzig \\ Presenting Author: zzhang@geomar.de
}

Recent studies highlighted exceptionally large fluxes of trace elements and rare earth elements (eg. $\mathrm{Fe}, \mathrm{Nd}$ ) delivered to the eastern South Atlantic by the Congo River Plume. At the same time the data revealed unknown contributions from river-borne particles and/or shelf sediments. In this work, dissolved barium $\left([\mathrm{DBa}] ; \delta^{138} \mathrm{Ba}\right)$ and silicon ([DSi]; $\left.\delta^{30} \mathrm{Si}\right)$ concentrations and stable isotopes are combined to evaluate cycling of these elements in the Congo River Plume based on the same samples as the above studies taken during GEOTRACES cruise GA08.

The Congo River freshwater is characterized by distinctly light $\delta^{138} \mathrm{Ba}$ (mean $=0.05 \pm 0.05 \%$ ), resulting in a deviation of the $\delta^{138} \mathrm{Ba}-1 / \mathrm{DBa}$ pattern in the plume waters from the global seawater mixing line at high $\mathrm{DBa}$ concentrations. During estuarine mixing, $\mathrm{DBa}$ and $\delta^{138} \mathrm{Ba}$ show conservative behavior at salinities above 22. The effective DBa river endmember is estimated to be $57 \%$ higher than the measured value indicating a considerable contribution by particulate $\mathrm{Ba}$ desorption in the low-salinity zone. This matches the observation of large Nd and Hf fluxes released from Congo-derived particulate phases. The effective $\delta^{138} \mathrm{Ba}$ river endmember is comparable to the measured value suggesting that particulate $\mathrm{Ba}$ desorption releases a $\delta^{138} \mathrm{Ba}$ signature identical to the dissolved Ba pool. DSi and $\delta^{30} \mathrm{Si}$ appear to behave overall conservatively during the estuarine mixing but a detectable DSi addition with light $\delta^{30} \mathrm{Si}$ signature (lighter than $1.01 \%$ ) is observed at salinities between 28 and 32 . This light signal might drive from the dissolution of river-borne amorphous silica or of detrital sediments on the shelf. In contrast to the inconspicuous influence of light riverine $\delta^{138} \mathrm{Ba}$ signatures offshore, the light riverine $\delta^{30} \mathrm{Si}$ signal can be tracked at a distance of $1000 \mathrm{~km}$ away from the river mouth, as supported by the rapid advection of the plume. The river-derived $\delta^{30} \mathrm{Si}$ and $\delta^{138} \mathrm{Ba}$ signatures are thus decoupled in the offshore region where $\delta^{30} \mathrm{Si}$ continuously increases to values of $\sim 3.00 \%$ as a function of progressively increasing DSi utilisation whereas $\delta^{138} \mathrm{Ba}$ remains relatively constant at $\sim 0.60 \%$ indicating limited removal of $\mathrm{DBa}$. 